\title{
High-yield Secretion of the Recombinant Sweet-Tasting Protein Thaumatin I
}

\author{
Tetsuya MASuda ${ }^{1,2 *}$, Nobuyuki Ide ${ }^{1}$, Keisuke Ohta ${ }^{1,2}$ and Naofumi KitabataKe ${ }^{1,2}$ \\ ${ }^{1}$ Department of Natural Resources, Graduate School of Global Environmental Studies, Kyoto University, Uji, Kyoto 611-0011, Japan \\ ${ }^{2}$ Division of Food Science and Biotechnology, Graduate School of Agriculture, Kyoto University, Uji, Kyoto 611-0011, Japan
}

Received May 12, 2010; Accepted July 27, 2010

Thaumatin, an intensely sweet-tasting protein used as a sweetener, was secreted by the methylotrophic yeast Pichia pastoris. Approximately $100 \mathrm{mg} \mathrm{L}^{-1}$ of recombinant thaumatin I was obtained using an expression vector which possesses three copies of the thaumatin gene containing the 22 -amino acid presequence. Expression yield was about three-fold higher than when the $\alpha$-factor secretion signal from Saccharomyces cerevisiae was used. The circular dichroism and tryptophan fluorescence spectra for recombinant thaumatin I were almost the same as those for plant thaumatin. Large amounts of homogeneous recombinant thaumatin allowed for preparation of high-quality crystals in the presence of cryoprotective glycerol used in high-resolution $x$-ray structural analysis to help further understand the perception of the sweet taste of thaumatin.

Keywords: thaumatin, sweet-tasting protein, sweetness, Pichia pastoris, pre-sequence, fermenter

\section{Introduction}

Thaumatin is a sweet-tasting protein isolated from the arils of Thaumatococcus daniellii Benth, a plant native to tropical West Africa (van der Wel and Loeve, 1972). Analysis of the purified sweet proteins shows that thaumatin consists of five intensely sweet forms, with two major components (thaumatin I and II) and three minor components (thaumatin $\mathrm{a}, \mathrm{b}$, and c). The difference in the five variants can be attributed to their isoelectric points (van der Wel and Loeve, 1972). On a molar basis, all of these forms are nearly 100,000 times sweeter than sucrose. Thaumatin I consists of a single chain protein of 207 amino acid residues and neither carbohydrates nor unusual/modified amino acids are contained in the molecule (Iyengar et al., 1979). Since thaumatin is a non-toxic protein and constitutes the principal part of the fruit (at least $20 \%$ of the aril dry weight), local people in West Africa have been using it for its sweetness, flavor enhancement, and synergistic properties in food products (Etheridge, 1994).

The nucleotide sequence of thaumatin I and II from cloned cDNA showed that thaumatin was translated as a prepro form with both a 22-amino acid hydrophobic N-terminal extension and an acidic 6-amino acid-long carboxyl terminal extension (Ide et al., 2007b, Edens et al., 1982). The deduced

*To whom correspondence should be addressed.

E-mail: t2masuda@kais.kyoto-u.ac.jp amino acid sequence of thaumatin I is different from that of thaumatin II at five sequence positions (N46K, S63R, K67R, R76Q, and N113D). Thaumatin I and II can be separated by ion exchange chromatography (van der Wel and Loeve, 1972). Although the residue at the position 113 of thaumatin I was believed to be Asn, our recent study showed that this residue is actually Asp (Ide et al., 2007a).

To shed light on the mechanisms for eliciting sweetness of thaumatin, its three-dimensional structure was determined and found to consist of three domains (De Vos et al., 1985; Ogata et al., 1992). Recently, Asherie et al. (2009) also determined the atomic resolution of the structure using purified thaumatin I and demonstrated the importance of using pure protein and stereochemically pure precipitants in crystallizing thaumatin.

Due to the limitation of obtaining the natural source of thaumatin from plant $T$. daniellii Benth, alternative production systems are necessary to use it as a sweetener. Moreover, to elucidate the mechanisms for sweetness of thaumatin, production of homogeneous recombinant thaumatin by microorganism systems would be an optimal approach. In fact, there have been numerous attempts to produce thaumatin by microorganisms (Edens et al., 1982, Daniell et al., 2000, Edens and van der Wel, 1985, Illingworth et al., 1988, Illingworth et al., 1989, Lee et al., 1988, Hahm and Batt, 1990, Faus et al., 1997). However, most of them were insufficient 
in protein yield and/or an inactive (non-sweet) protein. In some studies, acceptable production yield was achieved using artificial genes with optimized codon usage encoding thaumatin II (Weickmann et al., 2004, Daniell et al., 2000), but the recombinant protein was obtained as insoluble inclusion bodies, thereby requiring a renaturation procedure using a reduced/oxidized glutathione system to obtain a soluble, correctly folded, and active thaumatin II. Another expression system using Aspergillus awamori has been attempted to satisfy the expression yield of recombinant thaumatin, but three forms of recombinant thaumatin that differ in one amino acid at the N-terminus were obtained, resulting in a non-homogeneous product (Moralejo et al., 1999, 2001, Lombraña et al., 2004).

We have been investigating the effects of the pre- and pro-sequence of the thaumatin gene on secretion and processing of the N-terminal residues of recombinant thaumatin from Pichia pastoris (Ide et al., 2007b). However, the property of each recombinant protein has not been fully characterized. To identify detailed structural aspects of the sweetness of thaumatin, we must determine the three-dimensional structure of homogeneous recombinant thaumatin as well as thaumatin mutants which could affect the threshold value of sweetness. Thus, extremely high level expression of homogeneous recombinant thaumatin I is required to prepare highquality crystals for $\mathrm{x}$-ray diffraction analysis for examination of the mechanisms for intensely sweet aspects of thaumatin.

In the present study, we investigated the properties of the $\mathrm{N}$ - and C-terminal ends of thaumatin and attempted highyield secretion of recombinant thaumatin I from P. pastoris to prepare high-quality crystals in the presence of cryoprotective glycerol for high-resolution structural analysis.

\section{Materials and Methods}

Materials and culture media Escherichia coli strain XL1-Blue or DH5 $\alpha$ competent cells were used for cloning, transformation, and propagation of the recombinant thaumatin plasmid (Stratagene, La Jolla, CA, USA or Toyobo, Osaka, Japan). Strains X-33 and SMD1168H of P. pastoris were obtained from Invitrogen (Carlsbad, CA, USA). Plasmid $\mathrm{pCR}^{\circledR} 2.1-\mathrm{TOPO}^{\circledR}$ and plasmid pPIC6 $\alpha \mathrm{A}$ were from Invitrogen. Ligation was performed using a ligation high (Toyobo). E. coli was cultured in LB medium ( $1 \%$ tryptone, $0.5 \%$ yeast extract, and $1 \% \mathrm{NaCl}, \mathrm{w} / \mathrm{v}$ ) or LB broth Lennox (Becton Dickinson, Sparks, MD, USA) and P. pastoris was grown in YPD medium or buffered minimal glycerol (BMG). Restriction enzymes and calf intestinal alkaline phosphatase (CIP) were purchased from New England Biolabs Inc. (Beverly, MA, USA) and Toyobo. Yeast extract, bacto pepton, bacto trypton, bacto agar, and yeast nitrogen base (YNB) without amino acids were obtained from Becton Dickinson. Thaumatin I was purified from crude thaumatin powder (Wako Pure Chemical Industries Ltd., Osaka Japan) as described previously (Kaneko and Kitabatake, 2000). The concentration of plant thaumatin I was determined spectrophotometrically with a UV-160A spectrophotometer (Shimadzu, Kyoto, Japan) in $5 \mathrm{mM}$ sodium phosphate buffer, $\mathrm{pH} 7.0$, using a molar extinction coefficient, $\varepsilon_{278}$, of $17,000 / \mathrm{M} \cdot \mathrm{cm}$ (van der Wel and Loeve, 1972). To obtain $\varepsilon_{278}$, a mass of 22,209 Da was used (Iyengar et al., 1979). All other chemicals were of guaranteed reagent grade for biochemical use.

Preparation of thaumatin variants Four different expression plasmids, pPIC6 $\alpha$-TH, pPIC6 $\alpha$-proTH, pPIC6-preTH, and pPIC6-preproTH, were used as templates (Ide et al., 2007b). The Pichia transformants were prepared as described before (Masuda et al., 2005).

Expression of thaumatin variants by a fermenter Fermentation was performed in a 3-L or 7-L fermenter (M-100, Tokyo Rikakikai Co. Ltd. or TS-M7L, Takasugi Seisakusho Co., Tokyo, Japan) under temperature and $\mathrm{pH}$ control (FC2000, Tokyo Rikakikai Co., Ltd.). The temperature was maintained at $29^{\circ} \mathrm{C}$ and the dissolved oxygen was maintained at above $20 \%$ by an oxygen supply unit (MOS-25, Tokyo Rikakikai Co., Ltd.). The $\mathrm{pH}$ was adjusted to 5.0 through the addition of $25 \%$ ammonium hydroxide. Glycerol batch phase was initiated by adding $5 \%$ of the initial fermentation volume of the culture grown overnight in BMG medium to 1.3 $\mathrm{L}$ or $3.5 \mathrm{~L}$ of fermentation basal salts medium containing $4 \%$ glycerol, $1 \%$ casamino acid and $0.435 \%$ PTM1 trace salts. After complete consumption of the glycerol in the medium, a glycerol-fed batch phase was initiated by the addition of 50\% glycerol containing 1.2\% PTM1 trace salts. The glycerol-fed batch phase continued for a further $8 \mathrm{~h}$. The methanol-fed batch phase was initiated to induce the recombinant protein. During the first $2 \mathrm{~h}$, the methanol feeding rate was $1 \mathrm{~mL} \mathrm{~L}^{-1}$ $\mathrm{h}^{-1}$ to adapt the cells to grow on methanol. After adapting the cells to methanol, the methanol feed rate was increased to 8.0 $\mathrm{mL} \mathrm{L}^{-1} \mathrm{~h}^{-1}$. The total induction time was $110 \mathrm{~h}$.

\section{Construction of multi-copies of the thaumatin gene}

Plasmid pPIC6-preTH containing both the pre-sequence of thaumatin and mature sequence was digested with $\mathrm{BamH} \mathrm{I}$ and $B g l$ II, yielding a fragment of about $2.0 \mathrm{~kb}$ (Fig. 7A). The digested fragment was isolated from 1.0\% agarose gels using Qiagen Gel extraction kit (Qiagen, Hilden, Germany). To construct the multimers of the thaumatin gene, pPIC6preTH was linearlized by digestion with $\mathrm{BamH}$ I. Linearlized pPIC6-preTH plasmid (approximately $4.0 \mathrm{~kb}$, Fig. 7A) was treated with CIP and then ligated with the $B a m H ~ I-B g l$ II-treated fragment. Transformation was performed using DH5 $\alpha$ competent cells. Positive colonies were screened by 
PCR and restriction enzyme treatment. The resulting plasmid contained two copies of the thaumatin gene and was named pPIC6/thaumatin M2 (Figs. 6 and 7B).pPIC6/thaumatin M2 was further digested by $\mathrm{BamH}$ I to yield the resulting linearlized plasmid of about $6.0 \mathrm{~kb}$ (Fig. 7B). The $\mathrm{BamH}$ I-treated pPIC6/thaumatin M2 was further treated with CIP and then ligated with the BamH I - Bgl II-treated fragment as mentioned above to construct pPIC6/thaumatin M3. With the same procedure, we constructed plasmids bearing 4 and 5 copies of the thaumatin gene, and named them pPIC6/ thaumatin M4 and pPIC6/thaumatin M5, respectively (Fig. 6, Fig. 7C). The pPIC6/thaumatin plasmids (M1, M3, and M5) were collected by Qiagen Maxi prep kit. Electro-competent P. pastoris SMD1168H was prepared as follows. P. pastoris was inoculated in $5 \mathrm{~mL}$ YPD medium overnight and subsequently in $100 \mathrm{~mL}$ YPD medium. Cells were collected by centrifugation $(1,500 \times g)$ at $4^{\circ} \mathrm{C}$ and washed with sterile water twice followed by washing with $1 \mathrm{M}$ sorbitol. After centrifugation, cells were resuspended in $0.2 \mathrm{~mL}$ of $1 \mathrm{M}$ sorbitol. A mixture of $80 \mu \mathrm{L}$ electro competent P. pastoris and $50 \mu \mathrm{g}$ plasmid was placed in $0.2-\mathrm{cm}$ cuvettes on ice. Electroporation was performed as mention above. Transformation were further attempted to express the recombinant thaumatin by the fermenter.

Purification of recombinant thaumatin (TH) The supernatant of the culture was dialyzed extensively against $5 \mathrm{mM}$ sodium phosphate buffer, $\mathrm{pH}$ 7.0. Subsequently, the dialysate was applied to the CM-Toyopearl 650M column (Tosoh Co., Tokyo, Japan). Recombinant thaumatin was eluted with a linear gradient from 0 to $500 \mathrm{mM} \mathrm{NaCl}$ in $5 \mathrm{mM}$ sodium phosphate buffer, $\mathrm{pH}$ 7.0. The fractions containing thaumatin were collected and precipitated with $70 \%$ ammonium sulfate.

Polyacrylamide gel electrophoresis (PAGE) SDS-PAGE was performed using a $13.5 \%$ gel according to the method of Laemmli (1970). Native PAGE was performed using a 7.5\% homogeneous native polyacrylamide gel for the basic protein (Reisfeld et al., 1962). After electrophoresis, gels were stained with Coomassie Brilliant Blue R-250.

$\mathrm{N}$-terminal sequence analysis $\mathrm{N}$-terminal sequence analysis was performed in a gas-phase sequencer (Procise 490, Applied Biosystems, UK) using the Edman degradation method. Sample (200 pmol) was transferred to PVDF membranes for analysis.

Circular dichroism (CD) spectra CD spectra were recorded with a J-720 spectropolarimeter (Jasco, Tokyo, Japan) at $25^{\circ} \mathrm{C}$ in $5 \mathrm{mM}$ sodium phosphate buffer, $\mathrm{pH}$ 7.0. The protein concentration was $4.5 \mu \mathrm{M}$, and spectra were obtained with a $1-\mathrm{mm}$ cell at wavelengths from 250 to $200 \mathrm{~nm}$.

Fluorescence spectra Tryptophan fluorescence spectra were recorded at $25^{\circ} \mathrm{C}$ with a fluorescence spectrophotom- eter (F-3000; Hitachi, Tokyo, Japan). The protein concentration was $1.125 \mu \mathrm{M}$. The excitation wavelength was $295 \mathrm{~nm}$ and the emission wavelength ranged from 300 to $450 \mathrm{~nm}$.

Sensory analysis The sweetness threshold of the samples was evaluated by a triangle test for taste absolute threshold (Masuda et al., 2005). Briefly, $5 \mathrm{~mL}$ test solution, which was prepared in $5 \mathrm{mM}$ sodium phosphate buffer $(\mathrm{pH}$ 7.0), was added to a paper cup. As a control, $5 \mathrm{mM}$ sodium phosphate buffer (pH 7.0) was used. Four to six subjects participated in the trial and evaluated the sample solutions based on the concentration on a scale from low to high.

Crystallization The purified recombinant thaumatin in ammonium sulfate was centrifuged at $8,000 \times g$, and the precipitate was dissolved in $20 \mathrm{mM}$ HEPES buffer ( $\mathrm{pH} 7.0$ ) containing $150 \mathrm{mM} \mathrm{NaCl}$, and then further purified by $\mathrm{HW}-50 \mathrm{~F}$ gel-filtration column (Tosoh Co.). The fractions containing thaumatin were collected and concentrated by Centricon 10 apparatus (Millipore, Bedford, MA, USA). The protein concentration was measured by NanoDrop ${ }^{\circledR}$ ND-1000 spectrophotometer (NanoDrop Technologies, Inc., Rockland, DE, USA). Crystallization was performed using the hanging-drop vapor-diffusion method. The hanging drops were prepared by mixing $5 \mu \mathrm{L}$ of $10-100 \mathrm{mg} / \mathrm{mL}$ protein solution with $5 \mu \mathrm{L}$ of reservoir solution ( $0.1 \mathrm{M} \mathrm{N}$-(2-Acetanido) iminodiacetic acid, 1.0 M potassium, sodium tartrate $(\mathrm{pH}$ 6.5-6.8) and $0-25 \%$ glycerol). All solutions were prepared with sterile water and filtrated with MILLEXGV membrane (Millipore).

\section{Results and Discussion}

Expression and characterization of thaumatin variants In our previous study, in order to clarify the effects of the pre/pro-sequence of thaumatin on its secretion and production efficiency in yeast $P$. pastoris, we constructed four different expression plasmids (Ide et al., 2007b). Although plasmid pPIC6 $\alpha$-TH contains the $\alpha$-factor signal sequence from Saccharomyces cerevisiae for secretion of recombinant protein, secretion of neither $\alpha$-TH or $\alpha$-proTH that contain the $\alpha$-factor signal sequence from $S$. cerevisiae was detectable by western blotting when cultured in baffled flasks (Ide et al., 2007b). However, approximately $30 \mathrm{mg} / \mathrm{L}$ of protein was obtained when $\alpha$-TH was cultured in a fermenter (Ide $e t$ al., 2007a).

In the present study, approximately $10 \mathrm{mg} / \mathrm{L}$ of $\alpha$-proTH was obtained. The results of SDS-PAGE suggested that the size of the band for $\alpha$-proTH was greater than those for plant thaumatin and pre-thaumatin (Fig. 1). The results of Nterminal sequence showed that two basic amino acids ( $\mathrm{K}$ and $\mathrm{R})$ were added at the N-terminus of $\alpha$-TH and $\alpha$-proTH. Although the Kex2 protease cleavage site (Lys-Arg) is located at the end of the $\alpha$-factor signal sequence, no processing oc- 


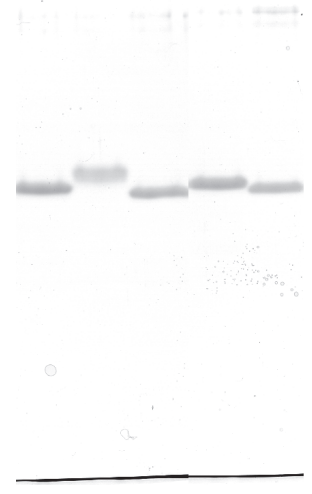

$\begin{array}{lllll}1 & 2 & 3 & 4 & 5\end{array}$

Fig. 1. SDS-PAGE of purified thaumatin variants from culture medium.

Lane 1: $\alpha$-thaumatin protein; lane 2: $\alpha$-pro thaumatin protein; lane 3: pre thaumatin protein; lane 4: prepro thaumatin protein; lane 5: plant thaumatin.

curred at this site; this may be due to the deficiency of Kex2 protease. These results are similar to the previous report by Moralejo et al. (1999) who used A. awamori as a host. Results of Native PAGE for positively charged proteins suggested decreased mobility of the band for $\alpha$-proTH compared to that for $\alpha$-TH (Fig. 2), indicating some additional acidic amino acid residues at the $\mathrm{C}$-terminus. Although individual bands of $\alpha$-proTH could not be separated by CM-chromatography, this decreased mobility corresponds to either the addition of four amino acids residues (LELE) or six amino acids residues (LELEDE) at the C-terminus (Fig. 2). Thus, the $\mathrm{C}$-terminus of the pro-sequence of $\alpha$-proTH appears to be incompletely processed compared to that of preproTH. Considering that thaumatin was also detectable in the membrane fraction of P. pastoris (Ide et al., 2007b), the differences in total surface net charges between $\alpha$-proTH and preproTH seem to be the result of processing at the $\mathrm{C}$-terminus of the pro-sequence.

Plasmids pPIC6-preTH and pPIC6-preproTH contain the 22-amino acid $\mathrm{N}$-terminal pre-sequence of thaumatin instead of the $\alpha$-factor signal sequence (Fig. 3). Approximately 60 $\mathrm{mg} / \mathrm{L}$ of preTH and $50 \mathrm{mg} / \mathrm{L}$ of preproTH were obtained in this study when cultured in a fermenter. Both preTH and preproTH had N-terminal residues, ATFE, which are identical to that of plant mature thaumatin, suggesting that the Nterminal pre-sequence was correctly removed by $P$. pastoris as in the case of plants (Fig. 3). The natural thaumatin gene

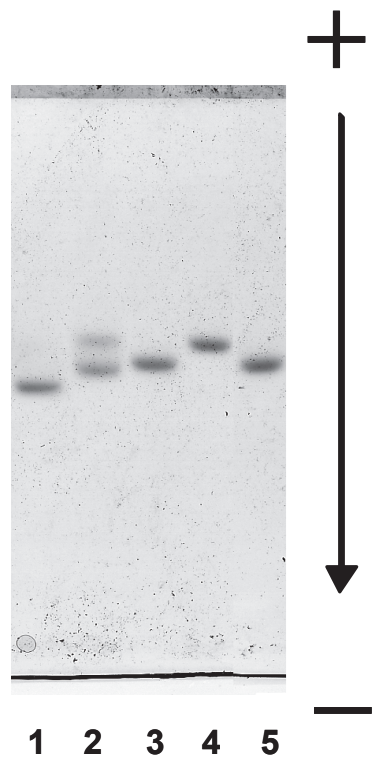

Fig. 2. Native-PAGE of purified thaumatin variants from culture medium.

Lane 1: $\alpha$-thaumatin protein; lane 2: $\alpha$-pro thaumatin protein; lane 3: pre thaumatin protein; lane 4: prepro thaumatin protein; lane 5: plant thaumatin.

contains an extra 22 hydrophobic residues as an N-terminal secretion signal (Edens et al., 1982, Ide et al., 2007b). Compared to the $\alpha$-factor signal sequence, the pre-sequence of thaumatin contains many hydrophobic amino acid residues (Fig. 3). Among these 22 amino acid residues of the presequence, there are 3 Ala, 5 Phe and 6 Leu residues. The $\alpha$-factor signal sequence consists of 85 amino acid residues, and its last 22 amino acid residues contain relatively hydrophilic residues, such as Glu, Lys, and Arg.

In contrast, the pre-sequence of thaumatin contains five consensus hydrophobic amino acid residues (FLLLL). The surface accessible area of the $\mathrm{N}$-terminal alanine residues of thaumatin is $18 \AA^{2}$, and only $15 \%$ of the side chain is exposed to the molecular surface (Kim and Weickmann, 1994). Taken together, the maintenance of the hydrophobic environment at the $\mathrm{N}$-terminal region of the thaumatin molecule

\section{$\alpha$-factor MRFP----- LFINTTLASIAAKEEGVSLE $\downarrow$ KRATFE-- Pre-TH MAATTCFFFLFFLLLLTLARA $\uparrow$ ATFE--}

Fig. 3. Comparison of the pre-sequence of thaumatin (Pre-TH) with the $\alpha$-factor signal sequence. Processing sites are indicated by arrows. The N-terminal sequence of the mature thaumatin is ATFE. The amino acid sequence of Pre-TH is deduced from AB265690 (GenBank). 


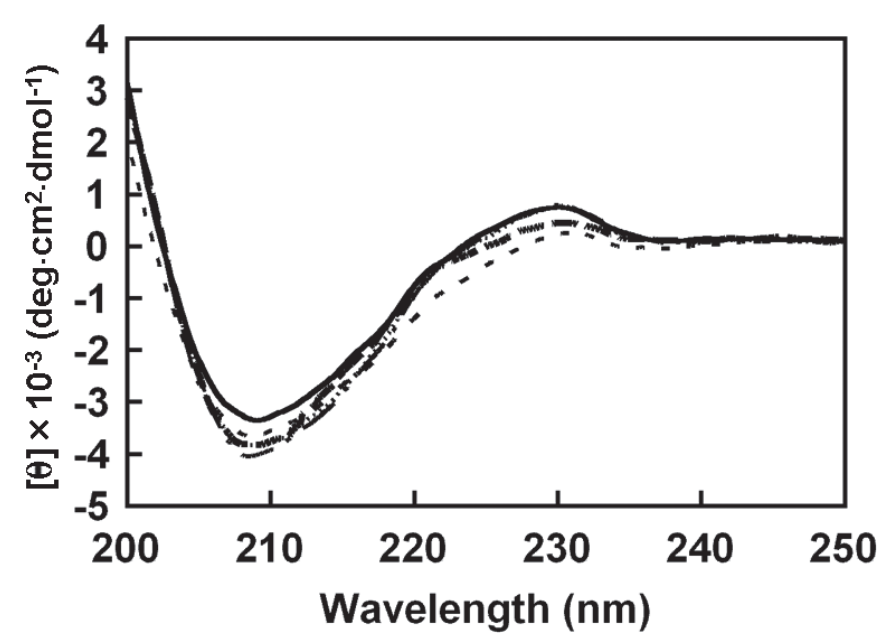

Fig. 4. CD spectra of thaumatin variants.

CD spectra of plant thaumatin I ), pre thaumatin (........), prepro thaumatin ( $\boldsymbol{-}-\boldsymbol{-})$, $\alpha$-thaumatin ( $\boldsymbol{-} \mathbf{-})$, and $\alpha$-pro thaumatin (--.--) were measured in $5 \mathrm{mM}$ sodium phosphate buffer, $\mathrm{pH}$ 7.0, as described in the Materials and methods. The data were collected three times and are given as the average mean residue ellipticity.

might be a requirement for stabilization of its structure. For this reason, the hydrophobic pre-sequence might be superior to the $\alpha$-factor signal sequence for secretion of thaumatin.

Characterization of thaumatin variants The CD spectra results indicated that the absolute ellipticities were similar among the four thaumatin variants (Fig. 4). These results demonstrate that no gross structural change in the secondary structure was induced by the introduction of additional amino acids at the $\mathrm{N}$ - and $\mathrm{C}$ - terminal regions. The changes in the environment around the Trp residues were also investigated by fluorescence spectra (Fig. 5). Fluorescence spectra show the same emission maximums for the thaumatin variants as that for plant thaumatin. This indicates that thaumatin variants do not differ remarkably in their secondary and tertiary structures from that of plant thaumatin. The threshold values of sweetness of $\alpha-\mathrm{TH}(51 \mathrm{nM})$ and PreTH ( $45 \mathrm{nM}$ ) have been previously determined by human sensory analysis (Ide et al., 2007a, b). In this study, we also determined the threshold value of sweetness for both PreProTH and $\alpha$-ProTH: $52 \pm 17$ $\mathrm{nM}$ and $60 \pm 21 \mathrm{nM}$, respectively. These results confirm that $\mathrm{N}$ - and C-terminal regions of thaumatin play no significant role in the elicitation of sweetness (Masuda et al., 2004) and the attachment of the pro-sequence at the $\mathrm{C}$-terminus does not affect the sweetness of thaumatin.

Effect of multi-copies of the thaumatin gene on expression efficiency Plasmids containing one to five copies of the thaumatin gene were constructed (Fig. 6). Each plasmid was analyzed by digestion of restriction enzyme (Fig. 7). Among

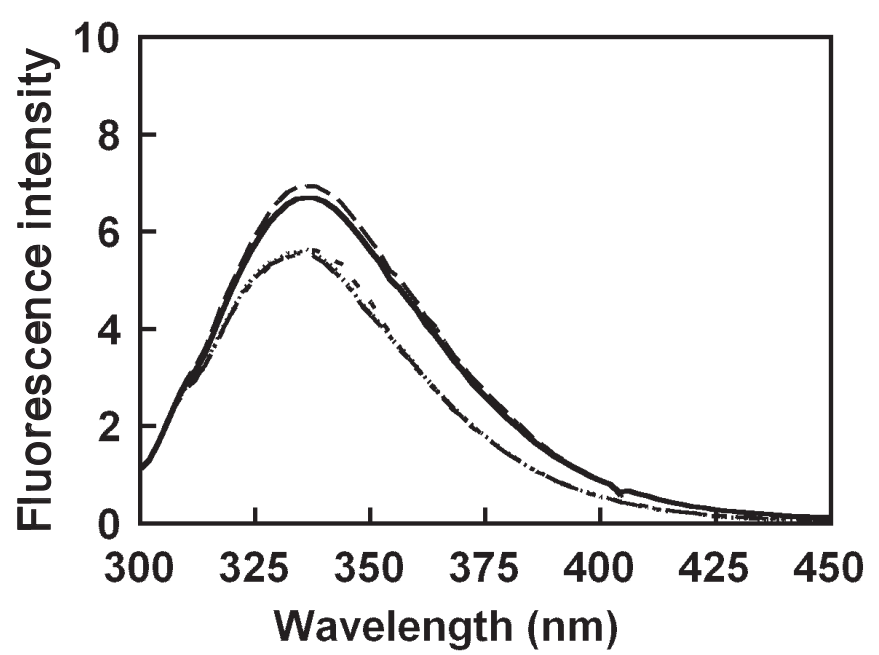

Fig. 5. Fluorescence spectra of thaumatin variants.

Plant thaumatin I ( $(\boldsymbol{C})$, pre thaumatin (........), prepro thaumatin ( $-\boldsymbol{-}$ ), $\alpha$-thaumatin ( $-\boldsymbol{-}$ ), and $\alpha$-pro thaumatin (--1--) were excited at $295 \mathrm{~nm}$ and the emission spectra were recorded at $25^{\circ} \mathrm{C}$.

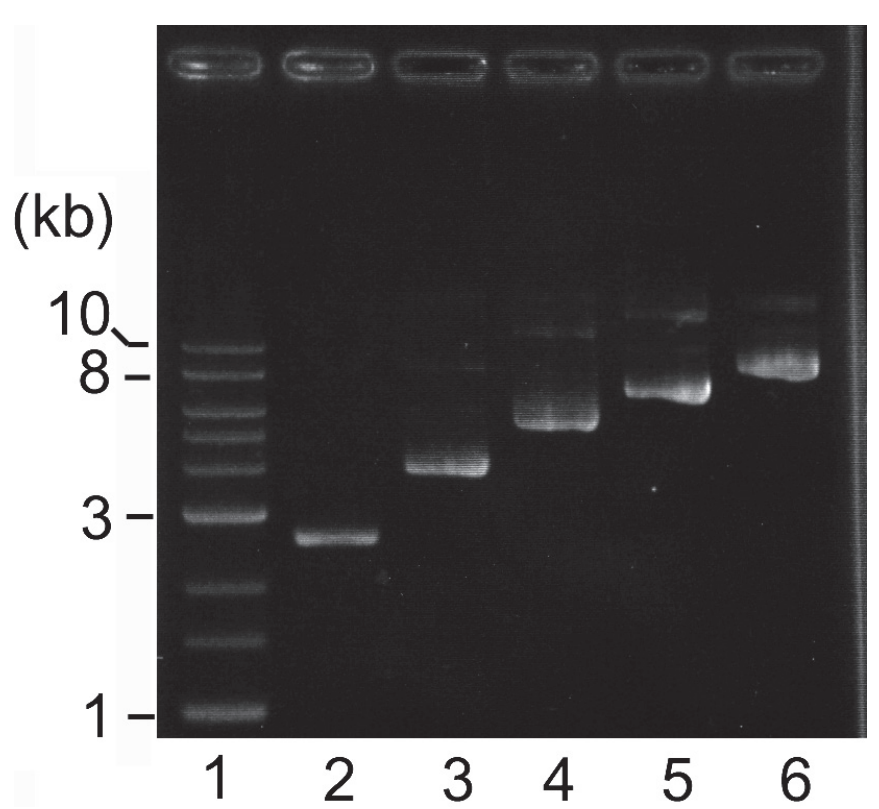

Fig. 6. Construction of multi-copy thaumatin genes.

Lane 1: 1-kb ladder marker; lane 2: Plasmid containing one copy of the thaumatin gene; lane 3: Plasmid containing two copies of the thaumatin gene; lane 4: Plasmid containing three copies of the thaumatin gene; lane 5: Plasmid containing four copies of the thaumatin gene; lane 6: Plasmid containing five copies of the thaumatin gene.

them, three plasmids (M1, M3, and M5) were propagated and extracted by Qiagen Maxi prep kit. Transformation was performed by electroporation and the transformants were selected on YPD plates containing $300 \mu \mathrm{g} / \mathrm{mL}$ blasticidin. 
(A)

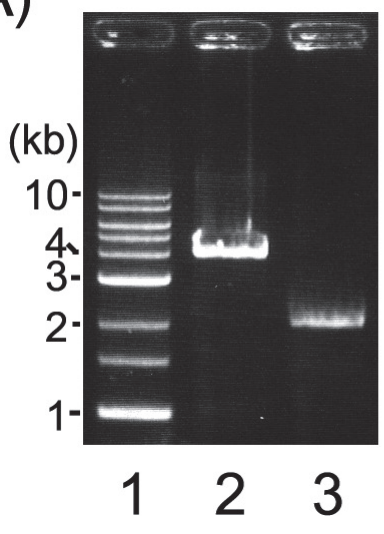

(B)

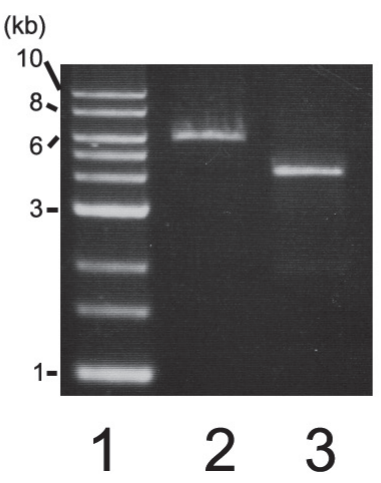

(C)

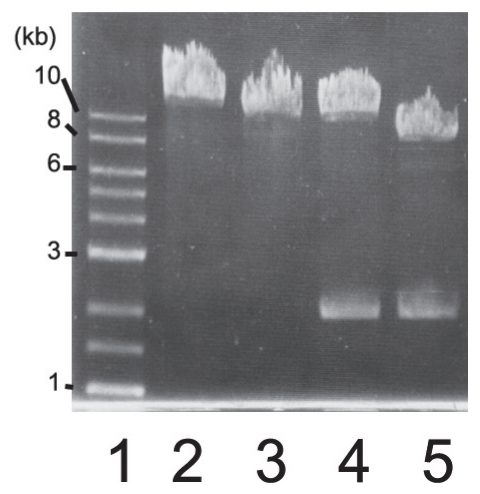

Fig. 7. Analysis of multi-copy genes by restriction enzymes.

(A) One copy of the thaumatin gene. Lane 1: 1-kb ladder marker; lane 2: $B a m H$ I digest; lane 3: $B a m H$ I - Bgl II digest. (B) Two copies of the thaumatin gene compared to one copy. Lane 1: 1-kb marker; lane 2: BamH I digest containing two copies of the thaumatin gene; lane 3: BamH I digest containing one copy of the thaumatin gene. (C) Four and five copies of the thaumatin gene. Lane 1: 1-kb marker; lane 2: BamH I digest containing five copies; lane

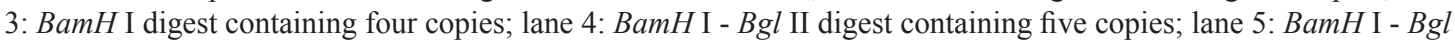
II digest containing four copies.

After one to two weeks, blastcidin-resistant colonies appear on M1 and M3. However, no colony appeared on M5. Since the size of the M5 plasmid is more than 12,000 bp (Figs. 6 and 7C), efficiency of transformation might be affected by this large sized plasmid. Next, we attempted to express one of the transformants using the fermenter. The supernatants of the culture medium at each fermentation stage were analyzed by SDS-PAGE (Fig. 8). Approximately $100 \mathrm{mg} / \mathrm{L}$ of recombinant thaumatin was obtained from a M3 colony. The results of CD spectra, tryptophan fluorescence spectra and sensory analysis of recombinant thaumatin were almost the same as those of plant thaumatin. Purified recombinant thaumatin was concentrated and crystallized using the hanging-drop vapor-diffusion method. It has been suggested that the rate of equilibration of protein solution by vapor diffusion is significantly reduced in the presence of glycerol. Charron et al. (2002) reported that it took at least 30 days to obtain the first crystal from unpurified thaumatin in the presence of $25 \%(\mathrm{v} /$ v) glycerol, although we obtained abundant crystals within two weeks in the presence of $25 \%(\mathrm{v} / \mathrm{v})$ glycerol and within a week in the presence of $10 \%(\mathrm{v} / \mathrm{v})$ glycerol. Recombinant thaumatin I produced in this study is a homogeneous sample and does not contain any other variants such as thaumatin II. The purity and homogeneous of the thaumatin sample may thus improve the capacity to form crystals.

The structural requirements for elucidating the sweetness of thaumatin molecules have been investigated from the perspective of chemical modification (van der Wel and Bel, 1976, Shamil and Beynon, 1990, Kaneko and Kitabatake,

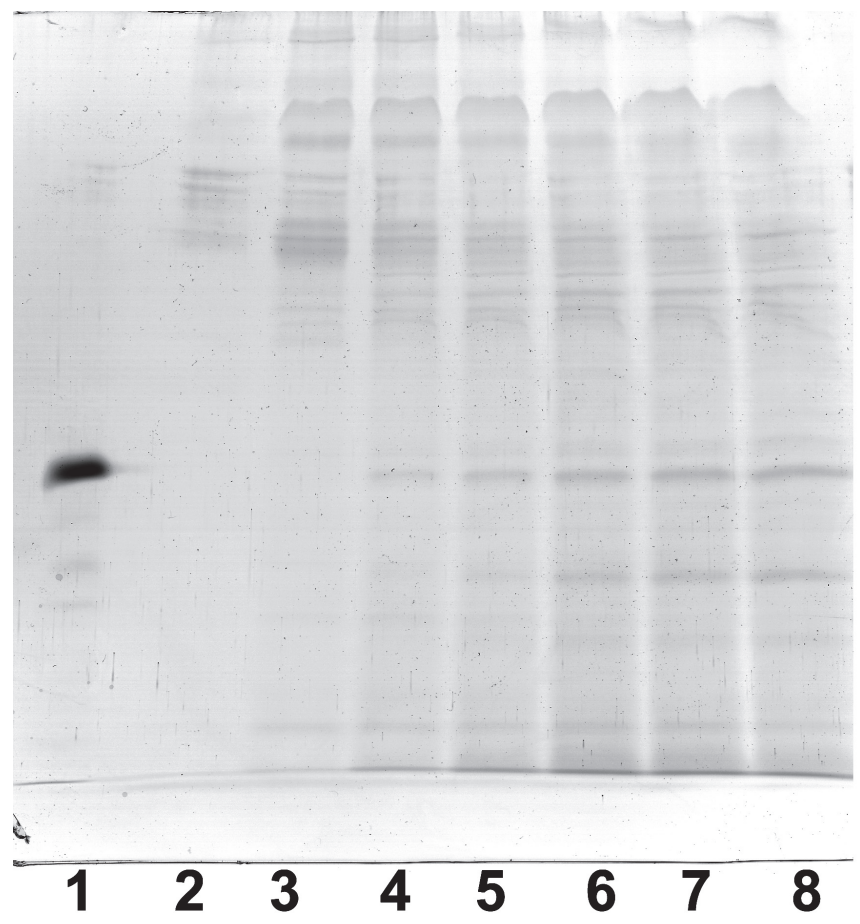

Fig. 8. SDS-PAGE analysis of culture medium at different induction times of Pichia M3-thaumatin.

Culture supernatant $(2 \mu \mathrm{L})$ was applied to each lane of SDS-PAGE. Lane 1: plant thaumatin (5 $\mu \mathrm{g})$; lane 2: glycerol batch phase; lane 3: before methanol induction $(0 \mathrm{~h})$; lane $4: 24 \mathrm{~h}$ after methanol induction; lane 5: $48 \mathrm{~h}$ after methanol induction; lane 6: $72 \mathrm{~h}$ after methanol induction; lane 7: $96 \mathrm{~h}$ after methanol induction; lane 7: $110 \mathrm{~h}$ after methanol induction. 
2001) and site-directed mutagenesis (Ohta et al., 2008). The results demonstrated that one side of the thaumatin molecule, the cleft-containing side, is important for eliciting sweetness of thaumatin, and the positively charged residues play significant roles in eliciting sweetness. High-yield secretion of recombinant thaumatin in the present study would provide sufficient amounts of samples for crystallization, allowing for further understanding of the perception of the sweet taste of thaumatin.

Acknowledgments This work was supported by a Grant-in-Aid for Young Scientist (B) Research from The Japan Society for Promotion of Science (T.M., no. 19780074) and by the Japan Food Chemical Research Foundation.

\section{References}

Asherie, N., Jakoncic, J., Ginsberg, C., Greenbaum, A., Stojanoff, V, Hrnjez, B. J., Blass, S. and Berger, J. (2009). Tartrate chirality determines thaumatin crystal habit. Cryst. Growth Des., 9, 41894198.

Charron, C., Kadri, A., Robert, M.C., Giegé, R. and Lober, B. (2002). Crystallization in the presence of glycerol; displaces water molecules in the structure of thaumatin. Acta Cryst., D58, 2060-2065.

De Vos, A.M., Hatada, M., van der Wel, H., Krabbendam, H., Peerdeman, A.F. and Kim, S.H. (1985). Three-dimensional structure of thaumatin I, an intensely sweet protein. Proc. Natl. Acad. Sci. USA, 82, 1406-1409.

Daniell, S., Mellits, K.H., Faus, I. and Connerton, I. (2000). Refolding the sweet-tasting protein thaumatin II from insoluble inclusion bodies synthesized in Escherichia coli. Food Chemistry, 71, 105-110.

Edens, L., Heslinga, L., Klok, R., Ledeboer, A.M., Maat, J., Toonen, M.Y., Visser, C. and Verrips, C.T. (1982). Cloning of cDNA encoding the sweet-tasting plant protein thaumatin and its expression in Escherichia coli. Gene, 18, 1-12.

Edens, L., Bom, I., Ledeboer, A.M., Maat, J., Toonen, M.Y., Visser, C. and Verrips, C.T. (1984). Synthesis and processing of the plant protein thaumatin in yeast. Cell, 37, 629-633.

Edens, L. and van der Wel, H. (1985). Microbial synthesis of the sweet-tasting protein thaumatin. Trends Biotechnol., 3, 61-64.

Etheridge, K. (1994). The sales and marketing of talin. In "Thaumatin,” ed. by M. Witty and J.D., Higginbotham. CRC Press, Boca Raton, Florida, pp. 47-59.

Faus, I., Patiño, C., del Río, J.L., del Moral, C., Barroso, H.S., Bladé, J. and Rubio, V. (1997). Expression of a synthetic gene encoding the sweet-tasting protein thaumatin in the filamentous fungus Penicillium roquefortii. Biotechnol. Lett., 19, 1185-1191.

Hahm, Y.T. and Batt, C.A. (1990). Expression and secretion of thaumatin from Aspergillus oryzae. Agric. Biol. Chem., 54, 25132520 .
Ide, N., Kaneko, R., Wada, R., Mehta, A., Tamaki, S., Tsuruta, T., Fujita, Y., Masuda, T. and Kitabatake, N. (2007a). Cloning of the thaumatin I cDNA and characterization of recombinant thaumatin I secreted Pichia pastoris. Biotechnol. Prog., 23, 1023-1030.

Ide, N., Masuda, T. and Kitabatake, N. (2007b). Effects of pre- and pro-sequence of thaumatin on the secretion by Pichia pastoris. Biochem. Biophys. Res. Commun., 363, 708-714.

Illingworth, C., Larson, G. and Hellenkant, G. (1988). Secretion of the sweet-tasting protein thaumatin by Bacillus subtilis. Biotechnol. Lett., 10, 587-592.

Illingworth, C., Larson, G. and Hellenkant, G. (1989). Secretion of the sweet-tasting protein thaumatin by Streptomyces lividans. J. Ind. Microbiol., 4, 37-42.

Iyengar, R.B., Smits, P., van der Ouderaa, F., van der Wel, H., van Brouwershaven, J., Ravestein, P., Richters, G. and van Wassenaar, P.D. (1979). The complete amino-acid sequence of the sweet protein thaumatin I. Eur. J. Biochem., 96, 193-204.

Kaneko, R. and Kitabatake, N. (2001). Structure sweetness relationship study of sweet protein thaumatin: Importance of lysine residues. Chem. Senses, 26, 167-177.

Kim, S.H. and Weickmann, J.L. (1994). Crystal structure of thaumatin I and its correlation to biochemical and mutational studies. In "Thaumatin," ed. by M. Witty and J.D., Higginbotham. CRC Press, Boca Raton, Florida, pp.135-149.

Lee, J.H., Weickmann, L.J., Koduri, R.K., Ghosh, D.P., Saito, K., Blair, L.C., Date, T., Lai, J.S., Hollenberg, S.M. and Kendall, R.L. (1988). Expression of synthetic thaumatin genes in yeast. Biochemistry, 27, 5101-5107.

Laemmli, U.K. (1970). Cleavage of structural proteins during the assembly of the head of bacteriophage T4. Nature, 227, 680-685.

Lombraña, M., Moralejo, F.J., Pinto, R. and Martín, J.F. (2004). Modulation of Aspergillus awamori thaumatin secretion by modification of bipA gene expression. Appl. Environ. Microbiol., 70, 5145-5152.

Masuda, T., Tamaki, S., Kaneko, R., Wada, R., Fujita, Y., Mehta, A. and Kitabatake, N. (2004). Cloning, expression, and characterization of recombinant sweet-protein thaumatin II using the methylotrophic yeast Pichia pastoris. Biotechnol. Bioeng., 85, 761-769.

Masuda, T., Ueno, Y. and Kitabatake, N. (2005). High yield secretion of the sweet-tasting protein lysozyme from the yeast Pichia pastoris. Protein Expr. Puri., 39, 35-42.

Moralejo, F.J., Cardoza, R.E., Gutierrez, S. and Martín, J.F. (1999). Thaumatin production in Aspergillus awamori by use of expression cassettes with strong fungal promoters and high gene dosage. Appl. Environ. Microbiol., 65, 1168-1174.

Moralejo, F.J., Watson, A.J., Jeenes, D.J., Archer, D.B. and Martín, J.F. (2001). A defined level of protein disulfide isomerase expression is required for optimal secretion of thaumatin by Aspergillus awamori. Mol. Genet. Genomics, 266, 246-253.

Ogata, C.M., Gordon, P.F., De Vos, A.M. and Kim, S.H. (1992). 
Crystal structure of a sweet tasting protein thaumatin I, at $1.65 \AA$ resolution. J. Mol. Biol., 228, 893-908.

Ohta, K., Masuda, T., Ide, N. and Kitabatake, N. (2008). Critical molecular regions for elicitation of the sweetness of the sweettasting protein, thaumatin I. FEBS J., 275, 3644-3652.

Reisfeld, R.A., Lewis, U.J. and Williams, D.E. (1962). Disk electrophoresis of basic proteins and peptides on polyacrylamide gels. Nature, 195, 281-283.

Shamil, S. and Beynon, R. J. (1990). A structure-activity study of thaumatin using pyridoxal 5'-phosphate (PLP) as a probe. Chem. Senses, 15, 457-469. van der Wel, H. and Loeve, K. (1972). Isolation and characterization of thaumatin I and II, the sweet-tasting proteins from Thaumatococcus daniellii Benth. Eur. J. Biochem., 31, 221-225.

van der Wel, H. and Bel, W.J. (1976). Effect of acetylation and methylation on the sweetness intensity of thaumatin I. Chem. Senses, 2, 211-218.

Weickmann, J.L., Blair, L.C. and Wilcox, G.L. (1994). High level expression of thaumatin in Saccharomyces cerevisiae. In "Thaumatin," ed. by M. Witty and J.D., Higginbotham. CRC Press, Boca Raton, Florida, pp. 151-169. 